\title{
Alunos com deficiência intelectual: reflexões sobre o conceito de desenvolvimento das funções psíquicas superiores e o papel da educação escolar na perspectiva histórico- cultural da escola de Lev Vigotski
}

\author{
Anna Maria Lunardi Padilha*
}

\begin{abstract}
Resumo
Reflete-se sobre o conceito de desenvolvimento humano para além das funções biológicas elementares, enfocando a necessidade de superação dos limites impostos por elas por meio da educação - seja no contexto das relações sociais seja no contexto específico da educação escolar, tomada como lócus privilegiado de desenvolvimento das funções psíquicas superiores. Da perspectiva histórico-cultural, entende-se desenvolvimento psíquico conforme a lei geral anunciada por Lev Vigotski, ou seja, a conversão das relações interpessoais no contexto de vida social, em funcionamento intrapsíquico de apropriação da cultura. A discussão aborda aspectos da teoria da escola de Vigotski acerca do desenvolvimento e da instrução.

Palavras-chave: Deficiência intelectual. Funções psíquicas superiores. Psicologia histórico-cultural. Pedagogia histórico-crítica.

\section{Students with intellectual disabilities: reflections on the concept of development of higher psychic functions and the role of school education in the Historical-Cultural perspective of Lev Vygotsky's school}

\begin{abstract}
It is offered reflections on the concept of human development beyond the elementary biological functions, focusing on the need to overcome the limits imposed by them through education - either in the context of social relations or in the specific context of schooling, considering the school as privileged locus of development of the higher psychic functions. From the historical-cultural perspective, psychic development is understood according to the general law announced by Lev Vygotsky, that is, the conversion of interpersonal relations in the context of social life, in intrapsychic operation of appropriation of culture. The discussion addresses aspects of Vygotsky's school theory of development and instruction.

Keywords: Intellectual Disability. Superior Psychic Functions. Historical-Cultural Psychology. Historical-Critical Pedagogy.
\end{abstract}

\section{Introdução}

O objetivo deste estudo é refletir sobre conceitos caros à escola de Vigotski, acerca do desenvolvimento humano, que possam ajudar a compreender as estreitas relações e a interdependência entre o desenvolvimento psíquico e a educação escolar, no que se refere ao desenvolvimento das funções superiores ou culturais. De acordo com a perspectiva histórico-cultural, o desenvolvimento das funções psicológicas superiores ou culturais acontece pela mediação semiótica como processo de apropriação da cultura historicamente construída. Assumir que o desenvolvimento cultural de qualquer indivíduo não se dá de forma natural instiga o pesquisador a mostrar o movimento do fazer-se que só acontece nas condições concretas de vida social.

O percurso da reflexão segue trazendo, primeiramente, os fundamentos da escola de
Vigotski acerca do desenvolvimento das funções psíquicas superiores. Tais fundamentos remetem a outras questões teóricas e práticas acerca do papel da educação, de modo geral, e da educação escolar. Serão discutidas duas delas: o conceito de meio e o papel do coletivo na vida da criança com deficiência. Finaliza-se abordando os nexos entre a psicologia histórico-cultural e a pedagogia histórico-crítica na educação das pessoas com deficiência.

Quando Lev Vigotski (1988) escreveu sobre os diferentes modos de conceber desenvolvimento e ensino/instrução ${ }^{2}$, que circulavam em sua época, apontou o que ele achava serem as teorias mais importantes. Um conjunto de teorias referia-se à concepção de que desenvolvimento e instrução/ensino são processos independentes. Aprender seria um processo exterior ao de desenvolvimento. Dessa forma, aprender não modifica o desenvolvimento, apenas "utiliza os resultados do desenvolvimento em vez de se adiantar 
ao seu curso e de mudar a sua direção" Exemplificou essa concepção com os estudos de Jean Piaget, para quem "a aprendizagem segue sempre o desenvolvimento" (VIGOTSKII, 1988, p. 103). O segundo grupo de teorias, segundo Vigotski - nesta mesma obra -, defende que aprendizagem é desenvolvimento e tem como um dos representantes Willian James", que diz que "a educação pode ser definida como a organização de hábitos de comportamento e de inclinações para a ação" e o desenvolvimento fica, então, "reduzido ao conjunto de reações". O indivíduo, para James, "é um conjunto de hábitos". (VIGOTSKII, 1988, p. 105).

Sobre o terceiro conjunto de teorias que tenta conciliar os dois primeiros, Vigotski diz que se trata de teorias dualistas de desenvolvimento: por um lado, depende da maturação, que depende do desenvolvimento do sistema nervoso, e, por outro, depende do ensino. Acerca dessa posição teórica, Lev Vigotski assume apresentar uma ampliação do papel do ensino/da instrução no desenvolvimento, não chegando, porém, a especificar a influência do ensino no desenvolvimento da criança. De todo modo, não aceitando nenhuma dessas posições como resolução do problema do desenvolvimento humano, nosso autor declara que o ensino promove algo "completamente novo ao curso do desenvolvimento". (VIGOTSKII, 1988, p. 110). Vigotski apresenta, então, sua elaboração da lei geral do desenvolvimento humano, que estará presente em inúmeros momentos de toda a sua obra.

Para uma compreensão mais clara do que venha a ser, para Lev Vigotski, desenvolvimento humano - desenvolvimento das funções propriamente humanas, ou, dito de outro modo, das funções psíquicas superiores/culturais, acompanhemos suas próprias palavras:

Podemos formular a lei geral do desenvolvimento cultural do seguinte modo: toda função no desenvolvimento cultural da criança aparece em cena duas vezes, em dois planos; primeiro no plano social e depois no psicológico, no princípio entre os homens como categoria interpsíquica e logo no interior da criança como categoria intrapsíquica. $\mathrm{O}$ dito se refere igualmente à atenção voluntária, à memória lógica, à formação de conceitos e ao desenvolvimento da vontade. Temos pleno direito de considerar a tese exposta como uma lei, mas a passagem, naturalmente, do externo ao interno, modifica o próprio processo, transforma sua estrutura e funções. Por trás de todas as funções superiores e suas relações se encontram geneticamente as relações sociais, as autênticas relações humanas. (VYGOTSKI, 1995 , p. 150 - grifos meus) ${ }^{4}$.

Como é que o psicólogo russo justifica sua lei, encontrando o verdadeiro nexo entre o que ele denomina de inter e o intrapsíquico? Com a sua teoria da mediação semiótica, tão cara a quem estuda a relação entre desenvolvimento e ensino. Tão cara igualmente como fundamento do papel da escola, onde todas as crianças devem aprender!

As funções psíquicas propriamente humanas (a atenção voluntária, a memória lógica, a formação de conceitos, a imaginação, a vontade, entre outras) não são produto da biologia ou da história filogenética pura da espécie. São sociais, são "relações interiorizadas de ordem social, são o fundamento da estrutura social da personalidade" (VYGOTSKI, 1995, p. 151). Vigotski segue os ensinamentos de Karl Marx, que afirma em sua tese VI sobre Feuerbach: "[...] a essência humana não é uma abstração inerente ao indivíduo singular. Em sua realidade, é o conjunto das relações sociais" (MARX, 1996, p. 13). Eis o materialismo histórico e dialético assumido por Lev Vigotski e sua escola. Sua lei geral do desenvolvimento explica a importância que dá ao coletivo na vida das crianças com deficiência. O que se converte em pessoal são as relações entre pessoas e seus significados e, portanto, o desenvolvimento caminha da socialização para a individualização. Do que é social para o individual. E não o inverso, como teorizou Jean Piaget. As funções humanas, no ambiente coletivo, se estruturam por meio da linguagem, pela mediação dos signos, pela mediação semiótica. "Da discussão nasce a reflexão" disse Vigotski, na obra citada. (VYGOTSKI,1995, p. 152).

Finalizo esta introdução com algumas ponderações de Vigotski acerca do desenvolvimento das pessoas com deficiência, segundo sua lei geral do desenvolvimento, para, em seguida, detalhar cada um dos pontos inicialmente propostos para este texto.

Sobre o desenvolvimento da criança com deficiência intelectual, Vigotski apresenta quatro teses: a primeira é que há uma base material das formas culturais do comportamento. No caso da deficiência intelectual, somente se edificam tais formas culturais por caminhos alternativos, por vias colaterais. A segunda tese esclarece que algumas funções psíquicas substituem outras, o que oferece possibilidades novas para o desenvolvimento. A terceira tese afirma que a base da estrutura das funções psíquicas superiores é a atividade mediadora dos signos. A quarta e última tese é sobre o domínio da própria conduta. Trata-se da insuficiência do 
desenvolvimento da vontade em indivíduos com deficiência intelectual - da dificuldade de dominar a própria conduta.

As quatro teses de Vigotski sobre o desenvolvimento devem ser cuidadosamente estudadas uma vez entendendo que, pela mediação semiótica - pelo uso de signos - é que será possível, na perspectiva aqui adotada, humanizar-se, tornar-se humano, dominar os conhecimentos da cultura e a si mesmo. Nós nos humanizamos porque nos apropriamos do acervo da cultura. E é esse o papel da educação escolar: ensinar - em quantidade e qualidade, em conteúdo e forma, os conhecimentos do acervo cultural para todas as crianças e jovens, sem e com deficiência.

\section{Fundamentos da escola de Vigotski acerca do desenvolvimento das funções psíquicas superiores}

Como já apontado, a humanização se dá com a apropriação da cultura por cada novo membro da sociedade. Nas relações estabelecidas desde o nascimento é que as crianças vão assimilando não só os conteúdos da experiência cultural, mas também os modos de pensar: "vai dominando os meios culturais particulares criados pela humanidade, no curso do desenvolvimento histórico" (VYGOTSKI, 1997, p. 347). Entendemos com esse psicólogo que não bastam quaisquer interações ou contatos humanos para que os novos membros da sociedade alcancem o domínio dos conhecimentos necessários ao desenvolvimento do que é propriamente humano. A qualidade das interações, das relações humanas é que faz a diferença entre os níveis de desenvolvimento. Como explica Pino ${ }^{5}$, estudioso da obra de Vigotski:

[...] o ser humano não é nem obra da natureza, nem produto da ação modeladora do meio e nem o resultado de qualquer processo interativo adaptativo do "tipo organismo-meio", onde a natureza polimorfa do meio desencadearia no organismo processos internos de construção de estruturas ou funções virtualmente presentes nele em forma germinal. Ele é uma "produção social" da qual participa na condição de sujeito. (PINO, 1993, p. 1 - grifo meu).

Claro está que, diferente das posições existentes à época de Vigotski já apontadas na introdução, o que está posto é que a perspectiva histórico-cultural do desenvolvimento humano tem como princípio que a reconstituição subjetiva da realidade objetiva, ou seja, que a passagem do inter para o intrapsíquico, não se dá por obra da natureza ou por um processo evolutivo natural, temporal e linear. Na esteira de Karl Marx, os autores da escola de Vigotski entendem essa passagem como um processo dialético de conversão do cultural em individual: a construção do humano do homem não é da ordem do biológico, mas do cultural, como uma segunda natureza. Marx (2010, p. 107) afirma:

Não apenas o material da minha atividade - como a própria língua na qual o pensador é ativo - me é dado como produto social, a minha própria existência é atividade social; por isso, o que faço a partir de mim, faço a partir de mim para a sociedade, e com a consciência de mim como um ser social.

A produção cultural é fruto do trabalho em um universo significativo, que é comunicável a cada nova geração pela educação. É trabalho semiótico. A apropriação do universo cultural é que define o conteúdo "do processo de constituição do ser humano da criança (o único significado aceitável do conceito de 'desenvolvimento')" (PINO, 1993, p. 2). $\mathrm{O}$ conceito de desenvolvimento deve, pois, ser compreendido como a constituição, em cada indivíduo singular, do que é propriamente humano e que foi desenvolvido, pelo trabalho da humanidade, na história - a cultura, ou seja, desenvolvimento é a conquista e o domínio do que já foi conquistado e dominado pelo ser humano. Isso porque o que a natureza biológica nos disponibiliza não nos é suficiente para sermos plenamente humanos. "A formação dos cinco sentidos é um trabalho de toda a história do mundo até aqui”. (MARX, 2010, p. 110 grifo do autor).

Uma vez definida a lei genética ${ }^{6}$ geral do desenvolvimento cultural, "o que é social e o que é cultural constituem duas categorias fundamentais na obra de Vigotski”, como afirma Pino (2000, p. 46). Trata-se da passagem do biológico para o cultural, na história da humanidade, no meio social da vida das pessoas, pela mediação do signo. A história de cada um deixa de ser obra individual, por fazer parte da história de toda a humanidade. O que é internalizado, convertido, apropriado por cada indivíduo não está disponível desde o princípio na vida de cada ser humano, mas se desenvolve ao longo de "sucessivas transformações geneticamente articuladas, na estrutura psíquica, constituindo, assim, todo o processo histórico de desenvolvimento das funções mentais superiores" (VYGOTSKI; LURIA, 2007, p. 27 - grifo dos autores). Onde buscar a fonte do desenvolvimento humano? Dizem esses mesmos 
autores que a busca deve se dar no entorno social da criança. Nas situações concretas de vida. Dessa forma, o papel da fala é "decisivo não só para compreender a estrutura da conduta, mas a sua gênese: a fala opera desde o começo do desenvolvimento infantil e se converte em fator mais fundamental e decisivo" (VYGOTSKI; LURIA, 2007, p. 28).

Alex Leontiev ${ }^{7}$ traz uma contribuição importante para a compreensão do conceito de desenvolvimento das funções psíquicas superiores desenvolvimento propriamente humano -, ou seja, desenvolvimento cultural. Em seu texto O homem e a cultura (1978), encontramos argumentos esclarecedores acerca do que estamos tratando neste texto. Explica ele que, no processo lento da evolução, o ser humano foi se libertando da estreita dependência das leis biológicas e hereditárias. Fora das condições concretas de vida social, não poderíamos, sequer, adquirir a posição vertical, afirma ele. Desse modo, são as leis sócio-históricas que passam a reger a vida humana.

Podemos dizer que cada indivíduo aprende a ser um homem. O que a natureza lhe dá quando nasce não basta para viver em sociedade. É-lhe ainda preciso adquirir o que foi alcançado no decurso do desenvolvimento histórico da sociedade humana (LEONTIEV, 1978, p. 267 - grifo do autor).

Com o suporte teórico de Marx e Engels como toda a escola de Vigotski -, Leontiev (1978) assume que "as relações humanas com o mundo, a visão, a audição, o olfato, o gosto, o tato, o pensamento, a contemplação, o sentimento, a vontade, a atividade, o amor, em resumo todos os órgãos da sua individualidade" são apropriações da realidade vivida na cultura. Apropriações (lembremos da lei geral do desenvolvimento: do inter para o intrapsíquico) que são o próprio processo de humanização. Ainda insiste em vários trechos que "as aptidões humanas não são dadas, mas que a criança aprende a atividade humana pelo processo da educação". (LEONTIEV, 1978, p. 272 - grifos do autor). A gênese do humano é social, porém, o que é social não atua como simples influência do meio como assumido por diferentes correntes da psicologia -, mas como constitutiva do gênero $H_{\text {omo }}{ }^{8}$. Dessa perspectiva é possível afirmar, como faz Pino (2005, p. 16 - grifo do autor), que "a consciência é fenômeno historicamente situado e ligado à atividade produtora do homem".

$\mathrm{O}$ conceito de desenvolvimento das funções psíquicas superiores/culturais, segundo Lev Vigotski e seus colaboradores, nos remete a outras questões teóricas e práticas acerca do papel da educação, de modo geral, e da educação escolar, de modo particular. No limite deste texto, abordaremos duas delas: o conceito de meio e o papel do coletivo na vida da criança com deficiência.

\section{O papel do meio e da escola como coletividade no desenvolvimento das funções psíquicas superiores}

A discussão sobre o papel do meio e da coletividade na formação humana demanda algumas considerações iniciais de suma relevância na perspectiva teórica aqui assumida, para entendermos o que venha a ser o desenvolvimento das funções psíquicas superiores, pois é disso que se trata quando falamos em desenvolvimento cultural.

Uma delas é o conceito de trabalho segundo K. Marx e F. Engels, que constitui o humano do homem e é base epistemológica da escola de Vigotski. A outra é o conceito de linguagem, também constitutiva do humano. É pelo trabalho e pela linguagem que os humanos se constituem como sujeitos: - o que só acontece em condições sociais e no ambiente coletivo. $\mathrm{O}$ trabalho é a atividade que possibilita a transformação da natureza e a transformação de si, nesse processo. A grande maioria de conhecimentos, habilidades e procedimentos do comportamento de que dispomos não resultam de sua experiência própria, individual, natural, mas são adquiridos pela assimilação da experiência histórico-cultural de sua geração. Esse traço "diferencia radicalmente a atividade consciente do homem do comportamento do animal" (LURIA, 1991, p. 73) $)^{9}$. Os estudos desse autor da escola de Vigotski indicam que a origem dessa atividade consciente na filogênese da espécie humana está no momento em que o homem conseguiu desenvolver o trabalho, que possibilitou a preparação e o uso de instrumentos e o surgimento da linguagem; trabalho e linguagem são constitutivos do humano do homem.

A linguagem funda outras habilidades que se configuram como estruturas mais complexas, que permitem a distinção entre os objetos, a discriminação, a atenção, a conservação e a memória deles na consciência, que podemos identificar no que Vygotski (1995) nomeou de funções psicológicas superiores ou complexas.

No texto A atividade consciente do homem e as suas raízes histórico-sociais, Luria (1991) propõe uma investigação sobre a gênese da atividade consciente do homem e constrói teses sobre a relação constituinte entre a categoria trabalho e a linguagem. 
Luria expõe três traços fundamentais na busca dessa argumentação, como resume Ramos (2017, p. 39). Primeiro, que a atividade consciente não está obrigatoriamente ligada a motivos biológicos. Como segundo traço fundamental, o homem não se orienta apenas pela sua percepção imediata, sua atividade consciente não é regulada pelo contato imediato com o seu meio. Sobre o terceiro traço, afirma que "a grande maioria dos conhecimentos e habilidade do homem se forma por meio da assimilação da experiência de toda a humanidade, acumulada no processo da história social e transmissível no processo de aprendizagem" (LURIA, 1991, p. 73 grifo do autor).

Em seus estudos, Ramos (2017, p. 42) conclui com Luria que é por meio da linguagem que foi possível estabelecer a habilidade da memória, da imaginação e do pensamento abstrato, "funções que possibilitam o distanciamento da experiência imediata, estabelecendo ideações que orientam sua ação, não mais por estímulos sensoriais, mas determinados pela sua consciência". A evolução, portanto, não depende mais somente do natural, do biológico, mas da capacidade de transmissão dos bens culturais.

Desde que uma criança nasce, ela está assimilando a história produzida pela humanidade. Não se trata de simples agir/reagir em contato com os objetos e com os outros membros da sociedade:

$\mathrm{O}$ modo pelo qual os homens produzem seus meios de vida depende, antes de tudo, da própria constituição dos meios de vida já encontrados e que eles têm de reproduzir. [...] O que eles são coincide, pois, com sua produção, tanto com $o$ que produzem como também com o modo como produzem. O que os indivíduos são, portanto, depende das condições materiais de sua produção. (MARX; ENGELS, 2007, p. 87 grifos dos autores).

György Márkus ${ }^{10}$, na mesma linha de $\mathrm{K}$. Marx e F. Engels, explica que o trabalho, a sociabilidade e a consciência são constituintes da essência humana. O trabalho para Marx, explica Márkus, "é autoatividade livre pela qual o homem forma, desenvolve e se apropria de suas próprias capacidades" (MÁRKUS, 2015, p. 92). Mas, sob as condições de alienação, o trabalho assalariado é imposto e externo ao indivíduo e acaba sendo apenas uma simulação de atividade livre:

[...] no capitalismo, a dependência do indivíduo sobre o todo social não significa a existência coletiva, e suas relações com os outros homens não são relações humanas pessoais que constituem um alicerce para uma vida coletiva, e a determinação social da sua existência não significa apropriação multilateral das necessidades e capacidades historicamente criadas por toda a humanidade (MÁRKUS, p. 93).

Na concepção de Vygotski (1997), o ser humano não é apenas um organismo inserido em um contexto social, mas é o próprio conjunto das relações sociais, sendo a sua natureza mental a representação da totalidade dessas relações internalizadas e transformadas em estruturas e funções individuais. Deduz-se daí que não se trata de qualquer meio e de qualquer coletivo na formação da consciência de cada um dos indivíduos. Há de se analisar as reais condições de vida; as reais condições de existência humana. O que somos e o que podemos chegar a ser vão além de simples condicionamentos ou respostas a técnicas de um ou outro processo educativo. Devemos perguntar: que condições são dadas no meio social e em que circunstâncias a coletividade é vivida no processo de desenvolvimento humano e no trabalho educativo com as novas gerações? As diferenças entre os humanos, a diversidade existente - para utilizar um termo atual - não estão dadas apenas pela natureza biológica ou pelo espaço onde vivem, mesmo que esses aspectos sejam também parte do que somos. O que se é, ou o que se pode vir a ser, tem relação direta com o complexo das relações sociais no espaço onde vivemos. Lembrando Antônio Gramsci ${ }^{11}$, somos uma série de relações ativas, que, todavia, não são relações mecânicas. "[...] conquistar uma personalidade significa adquirir consciência destas relações, modificar a própria personalidade significa modificar o conjunto destas relações" (GRAMSCI, 1989, p. 40).

As considerações anteriores são relevantes para prosseguirmos no intento de tratar do meio e do coletivo na formação humana das pessoas sem e com deficiência intelectual e do papel da escola.

Pelas informações do professor Boris G. Meshcheryakov (2010), entre 1933 e 1934, pouco antes de sua morte, Vigotski proferiu sete conferências $^{12}$ com apenas 100 cópias publicadas pela editora do Instituto Pedagógico Herzen, de Leningrado, em 1935. Vamos nos ater à quarta conferência, conhecida como Quarta aula: a questão do meio na pedologia ${ }^{13}$. O próprio Vigotski (2010) denomina de "aula" a sua fala aos educadores e desenvolve um dos possíveis conceitos de meio. Alertando seus ouvintes que o pedólogo deve estudar 
o significado do meio e sua participação no desenvolvimento da criança, diz:

[...] deve-se considerar o meio não como uma circunstância do desenvolvimento, por encerrar em si certas qualidades ou determinadas características que já propiciam, por si próprias, o desenvolvimento da criança, mas é sempre necessário abordá-lo a partir da perspectiva de qual relação existe entre a criança e o meio em dada etapa do desenvolvimento. (VIGOTSKI, 2010, p. 682).

$\mathrm{O}$ autor ressalta um aspecto que nos interessa bastante: a relação entre a criança e o meio em cada etapa do desenvolvimento. Quais as relações da criança com as pessoas ao seu redor, pela linguagem, em cada etapa da vida? Se, no início da vida, o mundo apresentado à criança ainda é pequeno e restrito; a depender da qualidade das relações, aos poucos o mundo pode se expandir:

Com os passeios, seu mundo aumenta e, cada vez mais, novas relações entre a criança e as pessoas que a circundam se tornam possíveis. Depois, o meio se modifica por força da educação, que o torna peculiar para a criança a cada etapa de seu crescimento: na primeira infância, a creche; na idade pré-escolar, o jardim de infância; na escolar, a escola. Cada idade possui seu próprio meio, organizado para a criança de tal maneira que o meio, no sentido puramente exterior dessa palavra, se modifica para a criança a cada mudança de idade. (VIGOTSKI, 2010, p. 683).

Na educação das crianças com deficiência, o meio pode se apresentar rico de experiências e conhecimentos ou reduzido, estreito e solitário. Que vivência os adultos proporcionam? Vigotski explica que vivências são entendidas como situações nas quais os adultos interpretam o mundo para a criança e, depois, esse mundo, que vai sendo internalizado, apropriado, significado, convertido em intrapsíquico, passa a ser interpretado pelas próprias crianças. Eis nosso papel como educadores e professores das crianças com ou sem deficiência: identificar quais as relações existentes entre a criança e o meio, como acontecem as vivências e de que forma a criança toma consciência delas e as concebe. Claro está que isso só será possível com a presença sistemática e intencional do processo de educação.

Neste ponto das reflexões, nos deparamos com a proposta da educação inclusiva. Acerca do conceito de inclusão escolar, Mendes (2017) destaca a realidade brasileira e suas afirmações podem contribuir para refletirmos sobre os conceitos de meio e de vivências. Diz a pesquisadora:

De fato, a educação que separa fisicamente os alunos é inerentemente discriminatória, desigual e, consequentemente, injusta. Por outro lado, $a$ educação que meramente iguala, oferecendo o mesmo ensino no mesmo ambiente, também pode ser discriminatória, desigual e injusta, se não responde às necessidades diferenciadas de alguns alunos. A ênfase atual na educação está na busca pela excelência nas escolas, gastando o mínimo possível, e tanto o aumento nas exigências e padrões de desempenho quanto as despesas, consideradas adicionais, para atender às necessidades do público-alvo da Educação Especial, complicam esse cenário porque impactam o financiamento da educação e questionam a função da escola pretendida pelos reformadores. (MENDES, 2017, p. 82 - grifos meus).

A sala de aula não está apartada do meio social mais amplo. Pelo contrário, as determinações políticas e econômicas precisam ser identificadas e, se necessário, combatidas, transformadas. A luta pela educação escolar das pessoas com deficiência supõe engajamento político. Vigotski, no texto A transformação socialista do homem, escrito em 1930, deixa clara sua posição revolucionária de um vir a ser - que também tem sido luta nossa:

[...] as leis de evolução histórica do homem diferem fundamentalmente das leis da evolução biológica e a diferença básica entre estes dois processos consiste no fato de que um ser humano evolui e se desenvolve como um ser histórico, social. Só uma elevação de toda a humanidade a um nível mais alto de vida social, a liberação de toda a humanidade, pode conduzir à formação de um novo tipo de homem. (VIGOTSKI, 2004, p. 9 - grifos meus).

A escola de modo algum é autônoma nos processos de transformação social ou da implementação de políticas públicas ${ }^{14}$ que possibilitem o desenvolvimento integral e integrado dos alunos, com ou sem deficiência. Se, ao que disse Vigotski na citação anterior, acrescentarmos as afirmações de Leontiev (1978, p. 273), mais clara fica a necessidade de tomada de posição política coletiva: "Quanto mais progride a humanidade, mais rica é a prática sócio-histórica acumulada por ela, mais cresce o papel específico da educação e mais complexa é a sua tarefa". Para ele, a relação entre o desenvolvimento histórico e uma educação de 
qualidade cada vez maior para todos é muito estreita e dialética.

Pino (2010, p. 750), analisando a Quarta aula de Vigotski, conclui que "O desenvolvimento da criança corre de par em par com as alterações do meio, e vice-versa". Há uma relação de reciprocidade. Essa ideia é reforçada pela afirmação de Vigotski (2018, p. 83): “Chegamos à conclusão de que o meio não pode ser analisado como um ambiente imóvel e externo em relação ao desenvolvimento, mas deve ser compreendido como mutável e dinâmico". E, ao final de sua Quarta aula, o autor resume sua teoria sobre o papel do meio no desenvolvimento das crianças: "O meio é fonte de desenvolvimento dessas características e qualidades especificamente humanas" (VIGOTSKI, 2018, p. 91).

Pensar em fonte de desenvolvimento é diferente de pensar em influência ou circunstâncias. Para Vigotski (2018, p. 90), o homem como ser social, cultural, simbólico - ser de trabalho e de linguagem - nunca se desenvolverá fora da interação com as outras pessoas: "O homem é um ser social e, fora da relação com a sociedade, jamais se desenvolveria as qualidades, as características que são resultado do desenvolvimento metódico de toda a humanidade".

As crianças com deficiência intelectual que chegam às escolas o fazem, na verdade, em um meio que está repleto de vivências (que vão determinar o papel de cada situação do meio para o desenvolvimento). Começam a fazer parte de um universo cujas condições histórico-culturais estão (ou deveriam estar) presentes de modo sequenciado, organizado, intencional, metódico. Há um objetivo a alcançar: o desenvolvimento das funções psíquicas superiores (domínio da vontade, atenção voluntária, memória lógica, imaginação, raciocínio, linguagem, leitura, escrita, cálculo, entre outras funções especificamente humanas).

É justamente no ambiente coletivo que se dão as relações significativas e promotoras do desenvolvimento. Vigotski, em publicação de 1930, fala da coletividade como fator de desenvolvimento das crianças com deficiência. Assumimos que a lei do desenvolvimento das funções superiores são as mesmas, tanto para as crianças deficientes como para as não deficientes. Se seguem a mesma lei - do interpsíquico para o intrapsíquico, então estamos diante de uma tarefa fundamental no caso das crianças e jovens com deficiência porque, ao reconhecermos essa lei, será necessária a organização de um conjunto de ações e de condições distintas, peculiares e específicas de ensino. Explica Vygotsky (1997, p. 213) que temos uma dupla tarefa: "estabelecer regularidades comuns e descobrir sua manifestação específica nas diferentes variantes do desenvolvimento infantil". As diferentes variantes do desenvolvimento infantil - longe de serem puramente biológicas - nascem e se formam no processo de desenvolvimento social, nas relações que se estabelecem nas "formas coletivas de colaboração" (VYGOTSKI, 1997, p. 219). Concluímos, portanto, que a memória, a atenção, o raciocínio, o domínio da vontade, a percepção, a imaginação, o desenvolvimento da personalidade são funções do desenvolvimento de sua conduta coletiva. Contrário ao adestramento de processos elementares, a inserção das pessoas com deficiência, desde muito cedo, na coletividade, promove a luta contra as dificuldades. Eis um importante ensinamento de Vigotski e de sua escola: é na atividade coletiva que se encontram as possibilidades de uma frutífera e promissora luta contra a deficiência. Privar as pessoas com deficiência da vida em coletividade é privá-las da fonte de desenvolvimento cultural. Essa privação, nosso autor classifica de "abandono pedagógico". (VYGOTSKI, 1997, p. 225).

Podemos visualizar claramente a importância do coletivo no trabalho pedagógico para Vigotski quando ele diz:

Poder compreender de um modo novo e concordante a verdadeira natureza dos fenômenos, o nexo entre a colaboração coletiva e o desenvolvimento das funções psicológicas superiores, entre o desenvolvimento da coletividade e da personalidade da criança com deficiência, constitui agora, para toda a nossa pedagogia da criança com deficiência, o ponto de apoio principal e básico. A pedagogia comunista é a pedagogia da coletividade. (VIGOTSKI, 1997, p. 234).

Já é sabida a preocupação da escola de Vigotski com a segregação dos alunos com deficiência, de acordo com os seus aspectos negativos, em um mesmo grupo. Vigotski argumenta a favor de um coletivo educacional e insiste no fato de que as escolas especiais (e no nosso caso, também as salas de aula onde as crianças com deficiência estão matriculadas) precisam estar preparadas teórica e didaticamente para encontrar "as formas ótimas de ações práticas, para resolver a tarefa histórica de superar, realmente, o atraso intelectual" (Ibidem, p. 132). 


\section{Os nexos entre a psicologia histórico-cultural e a pedagogia histórico-crítica na educação das pessoas com deficiência}

O terceiro e último aspecto a ser abordado neste texto diz respeito à psicologia e à pedagogia, cujos modos de ver o mundo - o desenvolvimento dos seres humanos, o trabalho e a linguagem, a sociedade, a educação, as possibilidades de vir a ser dos indivíduos e dos grupos humanos - têm os mesmos fundamentos, as mesmas bases teóricas e conceituais. No caso da psicologia histórico-cultural e da pedagogia histórico-crítica, ambas estão ancoradas num mesmo solo epistemológico - o materialismo histórico-dialético - e oferecem fundamentação sólida para esta nossa discussão.

A pedagogia histórico-crítica é a teoria pedagógica que torna possível estabelecer a relação de mediação necessária entre a prática educativa escolar e os fundamentos da psicologia históricocultural da escola de Vigotski, evitando assim uma instrumentalização simplista e direta dessa teoria para a pedagogia. Por sua vez, uma teoria pedagógica revolucionária deve cumprir a exigência própria da educação escolar, ou seja, a de mediação entre a obra da cultura e o desenvolvimento mental dos indivíduos, promovendo saltos de qualidade no desenvolvimento humano. As crianças e jovens com deficiência intelectual necessitam dessa mediação de modo especial e peculiar.

Vygotski (1997) aponta a perspectiva revolucionária de sua teoria com vistas ao futuro, cujo desenvolvimento, nas palavras dele, é um processo "socialmente orientado", ou seja, a conversão daquilo que é natural em cada ser em personalidade humana. Com a incorporação da cultura, diz ele, a criança não só adquire alguma coisa da cultura, mas assimila a própria cultura que "reelabora toda a conduta natural da criança e reorganiza de um modo novo todo o curso do desenvolvimento". (p.184). O autor bielorrusso (1993) aponta para um dos principais critérios do que venha a ser ensino fecundo: aquele que promove aprendizagens que elevam os modos de pensar, saindo de uma estrutura de generalização para outra.

Exemplificando: Bianca, a jovem com deficiência severa cuja história de transformação e de apropriação de conhecimentos foi contada em Práticas Pedagógicas na Educação Especial (PADILHA, 2007), tinha uma dificuldade bem acentuada de fazer previsões, de levantar hipóteses e imaginar situações futuras ou lembrar das passadas. Suas condições psíquicas para fazer generalizações estavam comprometidas e o que saísse do imediato presente parecia não mais existir. Bianca não estava mais frequentando uma escola porque, com seus 17 anos de idade, nunca se beneficiou da escola especial que frequentou por vários anos. $\mathrm{O}$ trabalho pedagógico sistemático e organizado, coerente com os princípios da psicologia histórico-cultural e da pedagogia histórico-crítica, foi mudando a organização da sua vida psíquica. As funções psíquicas superiores (linguagem, imaginação, previsão, memória lógica, atenção voluntária, imitação, comparação, domínio da vontade) foram se desenvolvendo interfuncionalmente e Bianca foi, aos poucos, por caminhos alternativos - por meio de estratégias didáticas que puxavam para frente seu desenvolvimento -, se constituindo em um sujeito que previa acontecimentos e sofria ou se alegrava com eles; solicitava dos adultos algumas mudanças de atitudes em relação a si mesma; pedia para aprender a escrever e, assim, poder mandar um bilhete para o rapaz por quem estava apaixonada, brigava por algumas promessas não cumpridas por seus pais. Foi acontecendo o que a teoria históricocultural explica como passagem de um nível de generalização para outro, elevação de um nível a outro de desenvolvimento das funções psíquicas culturais, complexas ou superiores - propriamente humanas.

Bianca era atendida em um Centro de Orientação Pedagógica, pela pesquisadora, mas, se estivesse matriculada em uma escola, necessitaria de uma programação direcionada para o desenvolvimento das funções culturais, por meio de estratégias didáticas, de acordo com o que Vigotski denominou de "ensino fecundo", e que fosse fiel ao que Dermeval Saviani explica sobre o trabalho educativo:

\begin{abstract}
O trabalho educativo é o ato de produzir, direta e intencionalmente, em cada indivíduo singular, a humanidade que é produzida histórica e coletivamente pelo conjunto dos homens. Assim, o objeto da educação diz respeito, de um lado, à identificação dos elementos culturais que precisam ser assimilados pelos indivíduos da espécie humana para que eles se tornem humanos e, de outro lado e concomitantemente, à descoberta das formas mais adequadas para atingir esse objetivo (SAVIANI, 2013, p. 13).
\end{abstract}

Davydov $^{15}$ (1988, p. 304) entende, como Vigotski, que "a entrada da criança na escola, é uma das transições (passagens) cruciais na sua vida" e a evidência disso está, justamente, nas mudanças que 
ocorrem na organização da vida da criança por estar em contato com o que há de mais desenvolvido na história: as ciências, as artes, a ética, ou seja, a atividade humana historicamente encarnada na cultura. A escola é, portanto, o lugar da elaboração conceitual, da saída do pensamento sincrético e caótico, em direção ao pensamento sintético, organizado, sistemático, conceitual, simbólico.

No entanto, quando se trata da escolarização das crianças com deficiência intelectual, lidamos cotidianamente com uma tendência a reduzir os objetivos de ensino, simplificar as tarefas propostas. Isso Vigotski já havia denunciado em relação a qualquer programa pedagógico. Em Sobre a análise pedológica do processo pedagógico, palestra proferida no Instituto Epstein de Defectologia Experimental, o autor disse: "Somente é boa a instrução que ultrapassa o desenvolvimento da criança. [...]". (VIGOTSKI, 1933 apud PRESTES, 2010, p. 283). Ultrapassar, avançar em direção ao conhecimento mais elevado, sair do lugar onde se está, e, para isso, utilizar métodos e técnicas adequados, os caminhos alternativos de que fala Vigotski ao abordar seus estudos sobre a deficiência intelectual. Vigotski (1995) explica que, se as crianças com deficiência intelectual não conseguem alcançar o desenvolvimento das funções culturais pelas mesmas vias que as crianças sem deficiência, é por meio de caminhos alternativos de vias colaterais que surgem novas possibilidades de desenvolvimento para elas. "Trata-se do emprego de signos, da inserção no mundo simbólico, do domínio da vontade e da própria conduta". (PADILHA, 2017, p. 11).

Para as crianças e jovens que necessitam de caminhos alternativos para vencer as limitações impostas - ou pelo biológico ou pelo contexto social estigmatizador -, a maior dificuldade é desligar-se do que está presente e do que é sensível, portanto, do seu cotidiano imediato. Reside aí, justamente, o trabalho pedagógico. Vygotski (1997), quando fala do trabalho educativo para e com as crianças com deficiência intelectual, faz um alerta aos educadores:

Precisamente porque a criança com atraso mental depende tanto, em sua experiência, das impressões concretas visuais e desenvolve tão pouco por sua própria conta o pensamento abstrato, a escola deve libertá-la do excesso do método visual-direto que serve de obstáculo ao desenvolvimento do pensamento abstrato e educar esses processos. Dito de outra forma, a escola não só deve adaptarse às insuficiências dessa criança, senão também lutar contra elas, superá-las (VYGOTSKI, 1997, p. 36 - grifo nosso).
O autor está falando da organização didática fundamentada em uma concepção de ensino e desenvolvimento que caminha na contramão da noção de adaptação, pelo menos em dois sentidos. Um deles refere-se ao fato de que o desenvolvimento da atividade consciente do homem não se dá, essencialmente, por processo adaptativo - como ocorre com os animais - porque, pela linguagem e pelo trabalho, o homem ultrapassa as impressões sensíveis imediatas das situações exteriores, ou seja, o excesso de impressões concretas visuais muito presentes nas propostas didáticas para a educação especial. Outro sentido é o de que "a organização do trabalho pedagógico deverá prever, sistematicamente e intencionalmente, atividades que promovam o desenvolvimento das funções superiores, que, para Vigotski, são as culturais". (PADILHA, 2015, p. 322).

Acredito que os ensinamentos da escola de Vigotski acerca do desenvolvimento das funções superiores têm na pedagogia histórico-crítica a mediação possível para que a escola desempenhe seu papel de fornecer aos alunos os meios apropriados para a elaboração conceitual. Com a análise realizada por Saviani (2008) sobre as ideias pedagógicas na história da educação brasileira, aprendemos sobre aquelas que, assumindo posturas de manutenção dos determinantes sociais de uma sociedade dividida em classes, contribuem para a conservação da forma como se organiza injustamente a sociedade. Como forma de romper com tal tendência dominante, a pedagogia histórico-crítica busca fazer resistência a essa condição limite de transformação e constrói, como premissa, a perspectiva de que a escola ocupa um papel de transformação social. Para mim, que aqui defendo a educação escolar de qualidade para todos, essa é a utopia que me move. A utopia da psicologia histórico-cultural do desenvolvimento que pode acontecer, na prática, por meio da mediação da pedagogia histórico-crítica.

Vygotski (1997, p. 153) afirma que “[...] o desenvolvimento cultural é a esfera principal onde é possível a compensação da deficiência". Se o desenvolvimento orgânico/biológico tem e/ou impõe limites, o desenvolvimento cultural, que supõe a escola e a instrução por caminhos alternativos, não tem limites. O Braille pode garantir a leitura e a escrita dos cegos. A Libras é a língua dos surdos. Os instrumentos cada vez mais desenvolvidos possibilitam o direito de ir e vir das pessoas com deficiências físicas.

Friso que o trabalho pedagógico contrahegemônico em relação ao ideário do neoliberalismo entende a educação tal como Saviani, citado acima e, 
se assim concebemos, lutamos incansavelmente pelas vias política e pedagógica - para que o saber escolarizado, os conhecimentos elaborados historicamente, cheguem a todos os alunos, com e sem deficiência. É preciso que no lugar de relações culturais empobrecidas para os alunos que menos tiveram condições de participação na cultura mais elevada, estejam presentes as condições mais ricas de formas e conteúdos escolares. Contudo, cabe destacar com Martins (2013), que tanto a psicologia histórico-cultural quanto a pedagogia históricocrítica não são perspectivas teórico-filosóficas alheias às condições objetivas da sociedade de classes vigente, com condições desiguais de humanização.

O ensino não deve se deter ao cotidiano nem se dirigir apenas para ele, ficando preso no que já foi conquistado pelos alunos. Trata-se de um caminho diametralmente oposto ao das pedagogias relativistas e neoliberais muito difundidas no campo educacional atual, visto que é de conhecimento científico que estamos falando em relação ao papel da escola e não da valorização de uma liberdade alienada dos indivíduos que têm objetivado formar nos escolares apenas a adaptação à realidade da qual já fazem parte (DUARTE, 2011) e que não lhes permite desenvolver-se e ser livres.

\section{Palavras finais}

Retomando o objetivo inicial deste texto, é possível concluir que refletir sobre o desenvolvimento das funções humanas superiores das novas gerações, com ou sem deficiências, sob a perspectiva da psicologia histórico-cultural e da pedagogia histórico-crítica, demanda estudo sistemático intencional - na formação inicial e na formação contínua - além de propostas práticas coletivas por parte dos professores e professoras, dos profissionais da educação bem como dos gestores públicos e das universidades. Negar às pessoas com deficiência intelectual o ensino dos conteúdos produzidos e historicamente sistematizados pela cultura humana é negar melhores condições objetivas concretas de vida para essas pessoas. O que almejo é a transformação social e a configuração de uma sociedade igualitária. A educação pode fornecer subsídios e fazer parte dessa luta maior!

\section{Notas}

1 Lev Semionovich Vigotski (1896-1934), um dos maiores nomes da psicologia do século $\mathrm{XX}$, dá importante contribuição à psicologia e à educação, sendo considerado um pensador da condição humana do homem, de acordo com Angel Pino (2000, p. 8). Adota-se no texto a grafia Vigotski, mas preserva-se nas citações e referências a grafia utilizada em cada edição.

2 De acordo com Zoia Prestes (2010), a palavra russa obutchenie, utilizada por Lev Vigotski, foi mal traduzida como aprendizagem. De acordo com sua tradução, realizada em interação direta com a escola de Vigotski na Rússia, a relação correta seria instrução: "atividade que gera desenvolvimento e por isso deve estar à frente do desenvolvimento e não seguindo o desenvolvimento como uma sombra. Trata-se também de um processo porque toda atividade, para Vigotski, é um processo. (p. 219). Mantém-se a palavra aprendizagem nas citações.

3 William James (1842-1910) foi um filósofo e importante psicólogo estadunidense. Um dos criadores da escola filosófica conhecida como Pragmatismo e um dos pioneiros da Psicologia Funcional.

4 As traduções de trechos das Obras Escogidas de Vigotski são de minha responsabilidade.

5 Angel Pino (1933-2013), estudioso da obra de Lev Vigotski e de sua escola, deixou muitas obras como legado de suas reflexões. Cf.: As marcas do humano: às origens da constituição cultural da criança na perspectiva de Lev S. Vigotski (2005).

6 Cf. Manuscrito de 1929 escrito por Lev S. Vigotski para a compreensão do que o autor conceitua de genético em sua teoria histórico-cultural. Diz ele: "Por trás de todas as funções superiores e suas relações estão relações geneticamente sociais, relações reais das pessoas". (VIGOTSKI, 2000, p. 25). Luria e Vigotski explicam que o enfoque genético para a explicação da mente humana tem a ver com o estudo do processo de sua construção e concluem que "as formações psíquicas mais complexas surgem das inferiores através do desenvolvimento". (VYGOTSKI; LURIA, 2007, p. 10 - grifos no original - tradução minha).

7 Alexis Leontiev (1903-1979), junto com Vigotski, Luria, Rubinstein e outros, desenvolve uma psicologia científica que leva em conta a parte clínica aberta aos problemas da pedagogia. Considerado um clássico dos temas da origem do homem, das determinações biológicas, do trabalho e da formação da consciência.

$8 \mathrm{O}$ termo Homo refere-se ao gênero de primatas antropoides ao qual pertence a espécie humana: Homo erectus, Homo habilis, Homo sapiens e Homo sapiens sapiens.

9 Alexander Romanovich Luria (1902-1977), 
companheiro de estudos de Vigotski, empenhou-se em estudar o pensamento, a linguagem, a percepção e a ação do ser humano depois dos transtornos produzidos por doenças/danos neurológicos.

10 G. Márkus (1934- 2016). Filósofo húngaro integrante da Escola de Budapeste.

11 Antônio Gramsci (1981-1937). Filósofo marxista italiano, jornalista e crítico literário. Detido em 1926, ficou o resto de sua vida prisioneiro dos fascistas. Escreveu os conhecidos Cadernos do Cárcere.

12 De acordo com Boris G. Meshcheryakov, conferências proferidas por Vigotski foram: 1 - O objeto da pedologia; 2 - Métodos característicos da pedologia; 3 - A doutrina da hereditariedade e do meio na pedologia; 4 - A questão do meio na pedologia; 5 - Leis gerais do desenvolvimento psicológico infantil; 6 - Leis gerais do desenvolvimento físico infantil e 7 - As leis do desenvolvimento do sistema nervoso. Os títulos das conferências foram modificados em 1996, quando de sua publicação. Não obstante, contêm expressões idênticas às utilizadas pelo próprio Vigotski, nas informações preliminares, e o conteúdo das exposições é o mesmo.

13 Pedologia é uma disciplina científica que estuda o desenvolvimento infantil.

14 As políticas públicas educacionais podem incentivar mudanças em vários campos da vida em sociedade e em sistemas educacionais, políticos e econômicos, porém, não são independentes das decisões do conjunto das políticas sociais mais amplas, que, por sua vez, são a expressão da própria sociedade.

15 Vasily Davydov (1930-1998) é um dos principais expoentes da escola de Vigotski na União Soviética. Seus estudos focam a relação entre o modo de organização do ensino e o desenvolvimento das funções mentais dos estudantes. Um de seus pressupostos é que o ensino é forma privilegiada para promoção do desenvolvimento do pensamento e da personalidade dos estudantes.

\section{Referências}

\section{DAVYDOV, V. V. Problemas do ensino}

desenvolvimental: a experiência da pesquisa teórica e experimental na Psicologia. Tradução J. C. Libâneo e R. A. M. Freitas. Editorial Progresso, 1988.

DUARTE, N. Fundamentos da pedagogia históricocrítica: a formação do ser humano na sociedade comunista como referência para a educação contemporânea. In: MARSIGLIA, A. C. G. (Org.). Pedagogia histórico-crítica: 30 anos. Campinas, SP: Autores Associados, 2011. p. 7-21.

GRAMSCI, A. Concepção dialética da história. Tradução C. N. Coutinho. Rio de Janeiro: Civilização Brasileira, 1989.

LEONTIEV, A. O desenvolvimento do psiquismo. Tradução M. D. Duarte. Lisboa: Horizonte, 1978.

LURIA, A. R. A atividade consciente do homem e suas raízes histórico-sociais. In: Curso de Psicologia Geral. v. 1. Tradução P. Bezerra. Rio de Janeiro: Civilização Brasileira, 1991. p. 71-84.

MÁRKUS, G. Marxismo e Antropologia: o conceito de essência humana na filosofia de Marx. Tradução M. Sacristán. São Paulo: Expressão Popular, 2015.

Teses sobre Feuerbach. In: . A Ideologia Alemã. Tradução J. C. Bruni e M. A. Nogueira. 10. ed. São Paulo: Hucitec, 1996. p. 11-14. . Manuscritos econômico-filosóficos. Tradução J. Ranieri. 4. ed. São Paulo: Boitempo, 2010.

MARX, K.; ENGELS, F. A ideologia alemã: crítica da mais recente filosofia alemã em seus representantes Feuerbach, B. Bauer e Stirner, e do socialismo alemão em seus diferentes profetas (1845-1846). Tradução R. Enderle, N. Schneider, L. C. Martorano. São Paulo: Boitempo, 2007.

MARTINS, L. M. O desenvolvimento do psiquismo e a educação escolar: contribuições à luz da psicologia histórico-cultural e da pedagogia histórico-crítica. Campinas, SP: Autores

Associados, 2013.

MENDES, E. G. Sobre alunos "incluídos" ou "da inclusão": reflexões sobre o conceito de inclusão escolar. In: VICTOR, S. L.; VIEIRA, A. B.; OLIVEIRA, I. M. (Orgs.). Educação especial inclusiva: conceituações, medicalização e políticas. Rio de Janeiro: Brasil Multicultural, 2017, p. 60-83.

MESHCHERYAKOV, B. Ideias de L. S. Vigotski sobre a ciência do desenvolvimento infantil.

Psicologia USP, São Paulo, 2010, n. 21, v. 4, 703-726.

PADILHA, A. M. L. Práticas pedagógicas na 
educação especial: a capacidade de significar o mundo e a inserção cultural do deficiente mental. 3. ed. Campinas: Autores Associados, 2007.

Educação inclusiva: já se falou muito sobre ela? Educação em Foco. Pacto Nacional pela Alfabetização na Idade Certa. Juiz de Fora: UFJF, Edição Especial, fev. 2015, p. 313-332.

Desenvolvimento psíquico e elaboração conceitual por alunos com deficiência intelectual na educação escolar. Revista Brasileira de Educação Especial. Universidade Estadual Paulista, v. 23, n. 1, jan./mar., Marília: ABPEE, 2017, p. 9- 20.

PINO, A. Processos de significação e constituição do sujeito. Temas em Psicologia,. v. 1, n. 1, Ribeirão Preto, abr. 1993.

Editorial. Revista Educação \& Sociedade. Ano XXI, n. 71. Campinas: Cedes, jul., 2000, p. 7-17. As marcas do humano: às origens da constituição cultural da criança na perspectiva de Lev S. Vigotski. São Paulo: Cortez, 2005.

A criança e seu meio: contribuições de Vigotski ao desenvolvimento da criança e à sua educação. Psicologia USP, São Paulo, 2010, n. 21, v. 4, 741-756.

PRESTES, Z. Quando não é quase a mesma coisa: traduções de Lev Semionovitch Vigotski no Brasil. Campinas: Autores Associados, 2010.

RAMOS, P. M. G. A concepção de linguagem do PNAIC e implicações metodológicas para o ensino da linguagem escrita: um estudo a partir da psicologia histórico-cultural. 2017. Dissertação (Mestrado). Universidade Metodista de Piracicaba,
Piracicaba, SP, 2017.

SAVIANI, D. História das ideias pedagógicas no Brasil. Campinas: Autores Associados, 2008.

. Pedagogia Histórico-Crítica: primeiras aproximações. Campinas: Autores Associados, 2011.

VIGOTSKI, L. S. Quarta aula: a questão do meio na Pedologia. Trad. Márcia Pileggi Vinha. Psicologia USP. São Paulo, 2010, n. 21, v. 4, 681-701.

. Sete aulas de Lev Vigotski sobre os fundamentos de pedologia. (Orgs.) (Trad.) Z. Prestes, E. Tunes, C. C. G. Santana. Rio de Janeiro: E-Papers, 2018.

VYGOTSKI, L. S. Obras Escogidas. Tomo III. Tradução L. Kuper. Madrid: Visor, 1995.

. Obras Escogidas. Tomo V. Fundamentos de Defectología. Tradução J. G. Blank. Madrid: Visor, 1997.

. A transformação socialista do homem. [1930] Tradução N. Dória. In: Arquivo Marxista na Internet, 2004. Disponível em:

<marxists.anu.edu.au/portugues/vygotsky/1930/ mes/transformacao.htm>. Acesso em: mar. 2018.

VYGOTSKI, L. S.; LURIA, A. R. El instrumento y el signo en el desarrollo del niño. Tradução P. del Rio. Madrid: Fundación Infancia y Aprendizaje, 2007.

VIGOTSKII, L. S. Aprendizagem e desenvolvimento intelectual na idade escolar. In: VIGOTSKII, L. S.; LURIA, A. R.; LEONTIEV, A. N. Linguagem, desenvolvimento e aprendizagem. Tradução M. P. Villalobos. São Paulo: Ícone, 1988, p. 103-117.

\section{Sobre a autora}

Anna Maria Lunardi Padilha: Professora voluntária da Universidade Federal Fluminense. Departamento de Psiquiatria Infantil. Foi docente do Programa de Pós-Graduação em Educação da Universidade Metodista de Piracicaba.

Recebido em junho de 2018.

Aprovado em outubro de 2018. 